\begin{tabular}{l|l}
\hline ISTEMA \\
ELETOONICO \\
DE REVISTAS \\
SER I UFPR
\end{tabular}

\title{
Depoimento de Caio Galvão de França ${ }^{1}$
}

Magda, guerreira companheira

Agradeço muito o convite para participar deste momento especial de celebração e de homenagem a uma pessoa tão especial - nossa Magda Zanoni - , amiga e companheira de boas lutas.

Recorro a um amigo mineiro - Juarez Guimarães - , para falar dos meus sentimentos. Juarez, ao tentar racionalizar os seus sentimentos diante da morte de seu pai, percebeu que eles apareciam - cada um a seu tempo ou ao mesmo tempo - como ausência, no gosto amargo da perda e do não poder mais encontrar; como evocação, lembrando como ele fazia as coisas, daquilo que ele gostava, o que dizia, o que gostava de contar; e, como incorporação, em diferentes momentos Juarez se via usando expressões do pai, manifestando preferências e gostos como os dele.

Percebi que todos esses sentimentos nos povoam ao nos lembrarmos de Magda Zanoni.
Hoje é um dia de homenagem ao Programa de Pós-Graduação em Meio Ambiente e Desenvolvimento (PPGMADE) da Universidade Federal do Paraná. Já são vinte e dois anos de um programa original e inovador. Algo, de fato, a ser celebrado. Um momento para celebrar e evocar a história do Programa.

E não haveria momento mais apropriado para homenagearmos Magda por toda a sua dedicação e paixão ao PPGMADE. Façamos de hoje um momento especial para sentirmos juntos sua ausência, para evocarmos suas ações e seu jeito de ser e incorporarmos seus valores e sentimentos.

Evoquemos essa guerreira incansável, revivendo o que cada um de nós compartilhou com ela.

Uma guerreira que assumiu como projeto de vida encarar os dilemas da civilização, tomar partido e fazer a sua parte para transformar o Brasil e o mundo. Para Magda, um outro mundo é possível, e isso exige de mulheres e homens

\footnotetext{
${ }^{1}$ Caio Galvão de França é Mestre em Sociologia pela Universidade Federal Minas Gerais. Analista Técnico de Políticas Sociais lotado na Secretaria Especial de Agricultura Familiar e Desenvolvimento Agrário. Foi coordenador do Núcleo de Estudos Agrários e Desenvolvimento Rural (2003 a 2006) e chefe de Gabinete do ministro do Desenvolvimento Agrário (2006-2010).
} 
uma generosidade militante, uma persistência paciente e a convicção de que não há escolha mais digna do que olhar de frente e com coragem tudo o que vem pela vida. Vinha daí sua profunda identificação com o Fórum Social Mundial. Magda e o Fórum compartilhavam uma consigna comum. Vinha daí sua coragem perante a vida. Nada a intimidava e não abria mão de sua autonomia.

Uma pessoa marcante, uma grande mulher, com uma imensa vitalidade. Um vulcão, um furacão criador, com toda a sua energia contagiante; e, ao mesmo tempo, uma menina atenta e curiosa.

Magda nos deixava claro que só se pode viver "tudo ao mesmo tempo agora", como cantam os Titãs. Outros versos, outras canções também têm muito a ver com Magda. Sempre é bom lembrar que "cada um sabe a dor e a alegria de ser o que é". Mas Magda guardava as suas dores e extravasava as suas alegrias, indignava-se com as dores dos povos do mundo - sempre nos recordava, nos últimos anos, do sofrimento do povo sírio - e compartilhava as dores de seus amigos.

Magda falava muito, de tudo. Poderia passar um tempão falando do Programa de Pós-Graduação em Meio Ambiente e Desenvolvimento, sobre o que o Ministério do Desenvolvimento Agrário devia fazer, sobre boas coisas feitas pela esquerda social pelo mundo, sobre experiências de intercâmbio de camponeses e das boas lutas.

Magda não falava muito de si, muito menos sobre suas dores - que foram imensas - e de seus feitos e realizações - que também foram inúmeros. Não recorria aos acon- tecimentos para ilustrar que tinha feito isso e aquilo. Quando falava de coisas das quais tinha participado, ou feito acontecer, ela não aparecia com o protagonismo que lhe correspondia. Não precisava se colocar em tudo; fazia porque acreditava, porque se sentia parte e se realizava nas coisas acontecendo.

Reli para esta sessão um artigo que ela escreveu, junto com sua amiga e parceira acadêmica Angela Duarte Damasceno Ferreira, intitulado "Outra agricultura e a reconstrução da ruralidade". O artigo faz parte do livro Para pensar outra agricultura, da Editora da UFPR, organizado pela Angela e por Alfio Brandenburg — esse, também, seu amigo.

Nesse texto elas registram com clareza política e objetividade acadêmica: a reflexão e a ação para construir um outro mundo parte da constatação de que há um sistema e uma ordem hegemônica, mas, também, de que outras formas de sociabilidade têm a possibilidade histórica de se realizar.

Isso vale para o conjunto da sociedade e vale para a reflexão sobre outras formas de agricultura. E elas seguem nos iluminando ao afirmar que é possível desbloquear formas de produção historicamente bloqueadas e subordinadas; que são possíveis diferentes padrões tecnológicos, novos padrões de relação entre técnicas, práticas agrícolas e modelos de organização da produção e apropriação da natureza mais adequados à reprodutibilidade dos recursos naturais e mais favoráveis à sustentabilidade das explorações agrícolas.

Para elas é possível garantir a segurança alimentar dos próprios agricultores e do conjunto da população; é possível repensar o rural 
como espaço de outras agriculturas e também como espaços de vida, trabalho e lazer, que podem ter outras lógicas. Sabem e dizem que é possível reconstruir ruralidades e recolocar a localidade como espaço de trabalho e vida em uma contraposição à dinâmica metropolitana; que é possível imaginar novas formas de articulação entre o rural e o urbano.

Elas nos dizem que é possível, portanto, tanto do ponto de vista teórico como em termos de políticas públicas, pensar em alternativas para construir outra agricultura que consolidem a agricultura familiar, o campesinato, os povos e as comunidades tradicionais como parte de um novo projeto nacional.

E deixam claro que essa compreensão "não pressupõe a ideia de que é possível substituir hegemonias num setor da sociedade - o rural, o agrário - , mas traz implícita a virtualidade de mudanças que podem tornar plural o quadro de alternativas existentes de desenvolvimento rural e agrícola".

Magda e Angela fazem uma aposta na agenda contra-hegemônica, na capacidade da ação coletiva de promover transformações.

Magda nunca deixou de ser uma militante; sempre fez política, a boa política, junto a organizações partidárias - como na Democracia Socialista, tendência do Partido dos Trabalhadores -, movimentos sociais e pessoas; onde estivesse e sempre. Fazer política para a Magda não era uma tarefa para depois do expediente; era uma atitude no seu trabalho acadêmico, na sua relação com os movimentos de mulheres, de ambientalistas, dos que lutam e fazem a reforma agrária, da agricultura familiar e camponesa, de solidariedade aos povos do mundo. Essa era sua atitude perante o seu tempo; essa era sua atitude de vida.

Para Magda não havia descontinuidades entre a trajetória acadêmica e a militância social. Evocava novos valores e buscava praticá-los no seu dia a dia, com as angústias e contradições que fazem parte, mas também com as alegrias e descobertas que essa atitude permite.

Como foi dito nessa sessão por várias pessoas, Magda invadia nossas vidas; da parceria no trabalho e na política não havia como não se gerar uma amizade cúmplice e solidária. Sua marca era a vitalidade e uma imensa capacidade de nos empurrar a querer e a fazer as coisas, todas as coisas.

Magda era dura na cobrança, pelo rigor, pelo compromisso e pela seriedade com que fazia tudo. Para ela, tudo era sempre possível e mostrava que juntos podíamos redefinir o próprio campo do possível.

Magda conseguia sempre ser contemporânea, ligada e ativa aos novos temas, mas sem cair em modismos ou navegar na trilha fácil do meio-termo, das concessões e das acomodações à ordem vigente.

Magda não tinha um único espaço, não se contentava com um nicho específico da política ou do conhecimento. Seu chão era do tamanho do mundo; ela era cidadã de todos os lugares.

Magda tinha lado e se tornava parte das causas e das lutas dos movimentos sociais, de organizações políticas de esquerda, e, ao mesmo tempo, era parte da universidade, dos fóruns acadêmicos e, também era parte da gestão pública, como, por exemplo, na sua experiência o Ministério do Desenvolvimento Agrário (MDA).

Uma mulher revolucionária, feminista, ecologista, anticapitalista, internacionalista. Brava gente! 
Secundarista no Rio Grande do Sul participou da resistência à ditadura militar. Esteve no Chile de Allende e escapou do golpe militar de Pinochet. Foi para a Suíça, e depois para a França e, ainda, não deixou de conferir a reforma agrária da Revolução dos Cravos em Portugal.

E é por isso que, quando o Partido dos Trabalhadores ganhou a eleição presidencial em 2002, Magda sabia que não podia ficar distante do Brasil. Tinha clareza dos desafios e da importância dessa conquista para o Brasil, para a América Latina e para o mundo.

Chegou em Brasília sem pedir licença, com um único objetivo: colocar o melhor de sua energia a serviço do projeto democrático e popular. Chegou ao MDA pelas relações políticas que tinha com a Democracia Socialista e com os novos dirigentes do ministério - Miguel Rossetto e Guilherme Cassel.

Chegou em abril de 2003 sem pedir e sem exigir nada; chegou animando, empurrando as pessoas, pois sabia que muita coisa boa poderia ser feita. E já chegou fazendo as coisas acontecerem. Chegou gerando inovações. Para contarmos com a colaboração da Magda, o MDA estabeleceu, pela primeira vez, uma cooperação com uma entidade acadêmica internacional, a Universidade Paris VII.

Conheci Magda no momento de sua chegada. Eu também acabava de chegar a Brasília, chegar ao MDA para coordendar o Núcleo de Estudos Agrários e Desenvolvimento Rural (NEAD). E minha primeira tarefa foi acolhê-la e viabilizar a permanência da Magda.

Viramos parceiros e camaradas; tornamo-nos amigos.

Magda tinha suas posições políticas, não abria mão de sua autonomia, de sua postura sempre crítica e atenta. Sempre teve uma imensa capacidade de aglutinar pessoas e mobilizar suas energias. Deixou muitas marcas em todos nós.

Não posso deixar de relembrar a longa e persistente batalha da Magda para viabilizar a versão em português do livro Histórias das agriculturas do mundo, de Marcel Mazoyer, com a colaboração generosa de sempre de Lovois Andrade, seu sobrinho e amigo. O professor Mazoyer é uma pessoa extremamente rigorosa e quem já assistiu alguma palestra dele no Brasil deve se lembrar de suas veementes interrupções para corrigir a tradução de suas falas. Imaginem o que foi fechar a revisão da edição brasileira com Mazoyer. Magda fez isso descobrindo artimanhas para que o professor amenizasse um pouco seu rigor nas sessões de revisão do livro. O trabalho começava difícil, quase tudo era criticado, e aos poucos ia ficando mais fácil e avançava. Assim saiu a edição brasileira dessa obra clássica, numa parceria, também inédita, do MDA com a Editora da Unesp.

Magda deixou muitas marcas boas no MDA, onde nos pressionou e nos levou a fazer coisas que não estavam na nossa agenda inicial. Aqui destaco quatro.

A valorização da cooperação e do intercâmbio tanto acadêmico como entre movimentos sociais. $\mathrm{E}$, preferencialmente, fazendo isso acontecer ao mesmo tempo. Um bom exemplo foi o projeto da queijaria no assentamento Nossa Senhora da Glória, em Herval, na metade sul do Rio Grande do Sul, desenvolvido no âmbito da cooperação descentralizada, envolvendo instituições universitárias (UFRGS e Universidade Paris Diderot), organizações não governamentais (Associação Holos e Soleil) e estruturas de governo do Brasil e da França. Assentados oriundos de outra região do estado, com outra tradição agrícola, experimentando o desafio 
de viver da pecuária familiar. $\mathrm{O}$ projeto começou lá atrás, durante uma das primeiras edições do Fórum Social Mundial. Magda conseguiu, junto ao governador Olivio Dutra, um helicóptero para levar Daniela Miterrand ao assentamento. Começava aí a cooperação descentralizada.

A queijaria está lá, funcionando e produzindo um gostoso queijo colonial, Mãe Natureza. E isso tem muito a ver com toda a dedicação da Magda e, especialmente, do Lovois.

Magda contou-me uma história que Lovois talvez pudesse contar com muito mais detalhes. Uma das missões de camponeses franceses ao assentamento coincidiu com a assembleia para criação da associação que tocaria a queijaria. Para variar, como sempre ocorre nesse tipo de discussão, muita confusão. De repente acaba a luz e a discussão é interrompida. Magda rapidamente providencia umas velas e, em vez da retomada da discussão, propõe uma sessão de degustação dos queijos trazidos pelos camponeses franceses. À luz de velas, o que se viu foi uma sessão de degustação, um intenso intercâmbio; a cada queijo provado vinha junto toda sua história e uma boa conversa sobre como ele era produzido. Depois disso, foi mais tranquilo retomar a assembléia e aprovar a criação da associação.

O segundo destaque sobre coisas que a Magda fez acontecer no MDA é a criação do Grupo de Estudos em Agrobiodiversidade (GEA) em 2004, que segue funciona e devidamente institucionalizado.O GEA remonta ao momento de aprovação do novo marco legal sobre biossegurança, que previu a liberação da utilização de sementes transgênicas sob determinadas condições e a criação da Comissão Técnica Nacional de Biossegurança (CTNBio), responsável por analisar todos os processos de liberação de pesquisa e de plantio. Apesar de constar na lei, o princípio da precaução era constantemente ignorado nos posicionamentos adotados por vários representantes na CTNBio, que, frequentemente, reproduziam em seus pareceres os pontos de vista e até o próprio texto das demandas das empresas. A correlação de forças era muito desfavorável, com um conjunto minoritário formado pelos representantes do MDA, do ministério do Meio Ambiente, do ministério da Saúde e por especialistas indicados pelas organizações da agricultura familiar e ambientais.

O discurso conservador e hegemônico tratava como obscurantista qualquer questionamento levantado na análise dos processos, mesmo que motivado pelo principio da precaução que constava do próprio marco legal recém-aprovado, e buscava desqualificar todos os trabalhos científicos que alertavam para os riscos dos organismos geneticamente modificados para a saúde e o ambiente.

Para elaborar os pareceres e organizar a intervenção na CTNBio, Magda reunia, nas vésperas de cada reunião, no MDA, no início no período da noite, os representantes de alguns ministérios, pesquisadores e de várias organizações e movimentos sociais, entre os quais: AS-PTA - Agricultura Familiar e Agroecologia; Greenpeace; Terra de Direitos; MST - Movimento dos Trabalhadores Rurais Sem-terra; MPA - Movimento dos Pequenos Agricultores, MMC - Movimento de Mulheres Camponesas. Ela coordenava a reunião, comprava a pizza ou a comida chinesa e animava a todos para encarar um tema superimportante em um um ambiente tão desfavorável.

Ante o enfraquecimento da Campanha Brasil Livre de Transgênicos - com a deslocamento da prioridade de alguns movimentos para a luta contra o uso de agrotóxicos - , o GEA constituiu-se no 
principal espaço de elaboração, discussão, divulgação e mobilização neste tema.

Um marco desse trabalho inventado pela Magda e pelos demais generosos e dedicados militantes do GEA foi o livro lançado em 2007, organizado por ela e Giles Ferment, intitulado Plantas geneticamente modificadas: riscos e incertezas. Com o livro em mãos, Magda percorreu o país convocando acadêmicos e movimentos a ampliar a participação no tema.

Um novo livro lançado pela equipe do GEA e pelo MDA ampliou o embasamento científico da luta pela aplicação do princípio da precaução e e pela restrição aos transgênicos. O livro intitulado Lavouras transgênicas — riscos e incertezas: mais de 750 estudos desprezados pelos órgãos reguladores de Organismos Geneticamente Modificados foi idealizado pela Magda e realizado pelos seus parceiros do GEA.

Magda mais uma vez fazia, ao mesmo tempo, ciência e política.

O terceiro destaque é sua dedicação para criar e fortalecer novas modalidades de ensino e pesquisa participativa para a agricultura sustentável. Seu encanto com o PPMADE é revelador desse interesse, dessa prioridade.

Insistia com o MDA e os movimentos de que era preciso dar visibilidade para as inovações orientadas para a produção sustentável; era preciso difundir experiências, estimular a reflexão crítica vinculada a experiências concretas; era preciso ampliar o intercâmbio e a cooperação técnica e científica, especialmente com outros países. E isso muito antes de a agroecologia ganhar visibilidade e conquistar adesão dos movimentos sociais e passar a ser objeto de novas políticas públicas.

E, como sempre, Magda propunha, pressionava-nos e fazia acontecer.
Seu último trabalho, Novas modalidades de ensino e pesquisa participativa para a agricultura sustentável, ainda não publicado, trata exatamente desses temas. Nele, Magda apresenta algumas experiências emblemáticas. No capítulo sobre as novas modalidades de ensino universitário para a agricultura familiar sustentável destaca o Curso de Especialização "Educação para a Agricultura Familiar", da Faculdade de Agronomia da Universidade Federal do Rio Grande do Sul (UFRGS) - mais uma das boas coisas que Magda fez acontecer mediante uma parceria do MDA com a Faculdade; a experiência da Escola Superior de Agronomia de Rennes, França, com seus novos currículos em licenciatura e pós-graduação; e o Curso de Educação a Distância intitulado "Planejamento e Gestão para o Desenvolvimento Rural (Plageder)", do Programa de Pós-Graduação em Desenvolvimento Rural da Universidade Federal do Rio Grande do Sul (PGDR/UFRGS), que tem em Lovois um dos grandes impulsionadores e organizadores. Em outro capítulo analisa a experiência de pesquisa participativa, que viabilizou o projeto da queijaria em Herval, e a experiência de organização autônoma de agricultores e agricultoras familiares em práticas de pesquisa, formação e difusão de conhecimentos desenvolvida pela Rede de Agricultura Sustentável (RAD), com atuação na região oeste da França.

E há mais coisas. Magda sempre fez ciência, na boa tradição acadêmica; e não desmerecia a dimensão política da ciência. E, entre as muitas boas coisas feitas por ela, trago como quarto destaque todo o seu empenho para constituir um movimento orientado para alcançarmos uma "Ciência Cidadã". Articulou um manifesto, cavou um espaço na Rede de Estudos Rurais e na Sociedade Brasileira para o Progresso da Ciência - SBPC. E lá estava a ideia 
lançada. E Magda prosseguiu e conseguiu dar visibilidade para a esta iniciativa no Fórum Mundial Ciência e Democracia, durante a Cúpula dos Povos na Rio +20, em 2012.

Para se ter uma ideia do alcance dessa iniciativa, transcrevo trechos do Manifesto².

A pesquisa é um bem público. Pertence ao público a escolha dos seus benefícios [...] Diante da mercantilização dos conhecimentos e da matéria viva, da desconsideração do saber popular, diversas mobilizações e iniciativas desencadearam um sobressalto democrático e um novo pacto social para uma ciência cidadã, responsável e solidária. Longe de se reduzir a um "aumento das crenças irracionais" ou a uma falta de informação ou de "cultura científica", pesquisadores, técnicos e movimentos sociais que reconhecem a necessidade da democratização da Ciência afirmam que uma ciência para todos deve se construir com todos, em um diálogo com os conhecimentos outrora desvalorizados.

[...] Queremos propor uma associação que possa motivar estes debates em vista de introduzir a questão do lugar da ciência na sociedade, no longo termo.
Muito mais se poderia dizer sobre as coisas que Magda fez acontecer.

Até quando pôde ela lutou; não desistia, pois nos dizia: "eu quero viver".

Evoquemos Magda, que nos ensina que viver é sempre viver intensamente.

Retomando aqueles sentimentos a que me referi no início, sentimentos associados à perda de alguém, proponho que para além de sentir a sua falta, das imensas saudades que curtimos, cada um de nós a seu modo, incorporemos Magda, sua atitude e sua generosidade.

Que esta mulher marcante, esse vulcão, com seus grandes ideais e uma imensa energia, siga habitando-nos, empurrando-nos e animando-nos a ultrapassar barreiras, a não nos acomodarmos e não desistirmos dos sonhos mais generosos, a ir além.

Que Magda nos inspire a fazê-los acontecer na imprevisível aventura da vida.

Magda, presente!

${ }^{2}$ Manifesto Ciência Cidadã. Disponível em: <http://www.movimentocienciacidada.org/manifesto>. Acesso em: 12 fev. 2016. 